\title{
The Clinicoetiological Profile of Neonatal Seizure at Level-II NICU in a Territory Care Hospital, Chhattisgarh
}

\section{Ganpat Jha', Pradeep Agarwal ${ }^{1}$, Subodh Kumar Saha1 ${ }^{1}$, Mitesh Chawda $^{1 *}$, Hitav Someshwar ${ }^{2}$, Ashish Wanare ${ }^{1}$, Ravi Prakash Pandey $^{1}$ and Bhushan Khadse ${ }^{3}$}

${ }^{1}$ Department of Pediatrics, Jawaharlal Nehru Hospital and Research Center, Bhilai, Chhattisgarh, India

${ }^{2}$ Department of Neurophysiotherapy, K. J Somaiya College of Physiotherapy, Mumbai, Maharashtra, India

${ }^{3}$ Department of Radiodiagnosis, Jawaharlal Nehru Hospital and Research Center,

Bhilai, Chhattisgarh, India

*Corresponding Author: Mitesh Chawda, Department of Pediatrics, Jawaharlal

Nehru Hospital and Research Center, Bhilai, Chhattisgarh, India.
Received: August 24, 2020

Published: October 16, 2020

(C) All rights are reserved by Mitesh Chawda., et al.

\section{Abstract}

We carried out a single centre, prospective, non-interventional observational study of consecutive neonates admitted in neonatal intensive care unit. We evaluated 150 neonates with seizures admitted to NICU in our centre from October 2015 to September 2017 over duration of two years. All subjects were evaluated on clinical basis; physical examination was done to look for vitals, blood pressure, and cyanosis.

Historical evaluation included demographic details and antenatal history to know the risk factors associated with occurrence of seizures in newborn. Special emphasis was given on risk factors like maternal age, gestation, birth order, prolonged or difficult labour, birth asphyxia, sepsis, maternal diabetes mellitus, and drug consumption during pregnancy. Appropriate laboratory investigations were sent including haemogram, blood sugar, serum calcium, serum magnesium, other blood biochemistries, blood culture and neuroimaging work up was done, if required. All data was then entered into a prestructured proforma/case history forms and statistical analysis was done.

Our study revealed that the most common etiology of seizures in our series was birth asphyxia. Metabolic disturbances were $2^{\text {nd }}$ most common etiology in which hypocalcemia was the most common type. Males outnumbered females, and seizures occurred most commonly in full term neonates as compared to preterm. The most common type of seizure was the subtle type followed by tonic and then clonic and myoclonic.

Birth asphyxia which was most common occurred on day of life 1. Metabolic seizures were most commonly occurred on day of life 4 to 7. Birth asphyxia was the most common etiology in both term and preterm babies. Phenobarbitone was the most common antiepileptic drug used in our study. All cases were also additionally managed for their underlying condition according to standard N.I.C.U protocols with special emphasis on hemodynamic stability.

Keywords: Neonates; Seziures; Asphyxia; Metabolic; Critical Care; Epilepsy

\section{Introduction}

Seizures in the neonatal period are the most common neurological emergency encountered and are associated with high mor- bidity and mortality. A seizure is a paroxysmal behaviour caused by hyper synchronous discharge of a group of neurons [1]. Neonatal seizures is overt manifestations of neurological dysfunction in the 
newborn and usually manifest as stereotypic muscular activity or autonomic changes. Neonatal seizures are poorly classified, underrecognized and often difficult to treat.

The immature brain is more prone to seizures than the mature brain and therefore seizures are more common in neonatal period than during any other time throughout life. The incidence of Neonatal Seizure is 2.8 per 1000 in infants with birth weights of more than 2500g; it is higher in preterm low birth weight neonates - as high as 57.5 per 1000 in very low birth weight infants [1]. Infants with neonatal seizure are at high risk of neonatal death or neurological impairment and epilepsy disorders in later life. Though, mortality due to Neonatal Seizure has decreased over the years from $40 \%$ to about $20 \%$, the prevalence of long-term neurodevelopment sequelae has largely remained unchanged at around 30\% [1].

The presence of neonatal seizures often signals an underlying ominous neurological condition, most commonly hypoxia-ischemia. The other common etiologies of neonatal seizures are stroke, intraventricular haemorrhage or intraparenchymal haemorrhage, meningitis, sepsis or metabolic disorders. In sick neonates, seizures are not easily recognized clinically and usually go untreated. New animal research suggests that neonates may exhibit some neuroprotection from prolonged seizures, but brief, recurrent seizures can result in significant permanent changes in the central nervous system, an increased risk of epilepsy, and long-term cognitive disabilities [2].

The neonate's central nervous system is anatomically and functionally immature. Although division of the cortical neurons stops at the second trimester of the pregnancy, it seems that glial cells, dendritic processes and myelinisation increase after birth and during the neonatal period. Numerous pathophysiologic mechanisms may adversely affect the growing and developing brain of neonates during this period; some of these conditions, possibly permanent, may include hypoxia, ischemia, infections, inflammations, malformations, maternal drug abuse, coagulative disorders and postpartum injuries such as birth trauma, hypoxia, ischemia, hypothyroidism, hyperthyroidism, polycythaemia, haemorrhage and meningitis [3-5]. Neonatal seizures are clinically significant and in a majority signify underlying etiology and there is only a small percentage that is idiopathic. It is critical to recognize neonatal seizures to determine their etiology and to treat them for 3 major reasons [6-8]:
- $\quad$ Seizures are usually related to significant illness, sometimes requiring specific therapy.

- Neonatal seizures may interfere with important supportive measures, such as alimentation and assisted respiration for associated disorders.

- $\quad$ Experimental data give reason for concern that the seizures per se may be a cause of brain injury.

Neonatal seizures present with varying manifestations like generalized tonic, multifocal, clonic and subtle activity. Even among trained observers, clinical neonatal seizures may be difficult to recognise and differentiate from either normal behaviours or abnormal movements of non-epileptic origin. Therefore, it is important to recognize the seizures and treat it, as delay in recognition and treatment may lead to brain damage. The time of onset of seizure has relationship with the etiology and prognosis. For example, birth asphyxia usually presents in the first three days of life whereas meningitis presents after first week. If baby convulses within hours of delivery, it signifies poor prognosis and brain damage [911].

Taking above points into consideration, this study was planned to know the etiology, onset and clinical manifestations of neonatal seizures has a significant role. The present study is done at a levelII NICU of institute in town place of Durg city of Chhattisgarh state.

\section{Aim of the Study}

The present study aimed to find out the spectrum of causes of neonatal seizures with its relationship to various parameters like gestational age, etiology, seizure type and the treatment provided to them.

\section{Methodology}

This prospective hospital based observational study was conducted in the level-2 Neonatal Intensive Care Unit of Department of Pediatrics, Jawaharlal Nehru Hospital and Research Centre Bhilai, Durg, Chhattisgarh. Ethical clearance was obtained from IEC before the study commenced. Informed consent was taken from the parents of the subjects. The sample size was calculated to be 150 samples, as per previous research, the incidence of neonatal seizure as reported by various studies ranges from $0.1-0.5 \%$ in Term neonates and $10-22.7 \%$ in Preterm neonates [12-14]. For calculation of sample size incidence of $0.1-0.5 \%$ is lower range for calculation of sample size, so due to limitation of resources we will take inci- 
dence of neonatal seizure from $10-22.7 \%$. For the present study, $\mathrm{P}$ $=$ prevalence of neonatal seizure therefore $\mathrm{p}=10$.so $\mathrm{q}=100-\mathrm{p}=90$, Sample size formula by Cochran [15] $n=4 \mathrm{pq} / \mathrm{L}^{2}$, Where $n=$ sample size, $\mathrm{p}=$ prevalence or proportion, $\mathrm{q}=100-\mathrm{p}, \mathrm{L}^{2}=$ permissible error in estimate of "p" $=5 \%$. With $10 \%$ non-respondents and Dropouts. We included neonates presenting with at least one of the following clinical type of seizures: generalized tonic, multifocal clonic, focal clonic or myoclonic seizures with or without accompaniment of subtle motor movements, apneas or autonomic changes or the sole combination of subtle motor and autonomic manifestation. Neonates with jitterness, spasms, benign sleep myoclonus were excluded. All cases included in this study were evaluated on following parameters. 1) History 2) Physical examination 3) Measurement of laboratory parameters.

\section{History}

Historical evaluation included demographic details and detailed antenatal history to know the risk factors associated with occurrence of seizures in newborn. Special emphasis was given on risk factors like maternal age, gestation, birth order, prolonged or difficult labour, birth asphyxia, sepsis, maternal diabetes mellitus, and drug consumption during pregnancy.

The following standard definitions and working threshold levels were considered while enrolling neonates with convulsions. All neonates whose parental consent was obtained were then included in the study.

A seizure in neonate was defined as: (a) Subtle seizure when neonate had jerking of eyes, blinking or fluttering of eyelid, staring look, sucking, chewing or smacking oro-buccal movements or apnoeic attack. (b) Multifocal clonic seizure when neonate had clonic convulsive movements migrating haphazardly from one limb to another. (c) Focal clonic seizure when the neonate has a well localized clonic convulsions. (d) Tonic seizure when, the neonate had generalized stiffening associated with stertorous breathing and occasional clonic jerks. (e) Myoclonic seizure when the neonate had sudden jerky movements.

Preterm baby was defined as a baby with a gestation of less than 37 completed weeks. LBW baby with a birth weight of less than 2500 gms (Up to and includes $2499 \mathrm{gm}$ ) Irrespective of the period of gestation.

- Hypoglycemia: The world health organisation now designates blood glucose "operational threshold" as less than or equal to $2.6 \mathrm{mmol} / \mathrm{l}$ and make no distinction between term and preterm infants [16].
- Hypocalcemia: Neonatal hypocalcemia is defined as total serum calcium level of $<7 \mathrm{mg} / \mathrm{dl}$ or an ionised calcium level of $<$ $4 \mathrm{mg} / \mathrm{dl}(1 \mathrm{mmol} / \mathrm{L})$. In very low birth weight (VLBW) infants ionised calcium levels of $0.8-1.0 \mathrm{mmol} / \mathrm{L}$ are common and are usually asymptomatic. In large infants and in infants of $>$ 32 weeks gestation symptoms readily appear at levels below $1 \mathrm{mmol} / \mathrm{L}$ [17].

- Hypernatremia: Hypernatremia is defined as sodium concentration more than $145 \mathrm{mEq} / \mathrm{L}$.

\section{Physical examination}

This included examination of vitals, 4 limbs BP, cyanosis, looking for associated malformations/syndromes, and systemic examination of all the major organ systems, anthropometric measurements to look for macro/microcephaly.

\section{Lab investigations}

- Following baseline investigation were done appropriately in our study cases.

- $\quad$ CBC and hemogram - To know polycythemia and hyperviscosity syndrome, underlying sepsis.

- Blood culture.

- $\quad$ Biochemical profile - serum calcium, serum electrolytes and blood sugar.

- CSF examination.

- $\quad$ Arterial blood gas analysis, pulse oxymetry monitoring.

- USG skull, fundus examination.

- Neuroimaging findings, EEG, inborn errors of metabolism workup depending on the likely diagnosis.

- BOA/BERA.

\section{Management}

All cases were also managed for their underlying condition according to standard N.I.C.U protocols. The protocol entailed the following that in an actively convulsing neonate, an adequate airway was maintained by providing oxygen by alternative devices like nasal prongs or hood or suctioning the airways or E.T Tube, along with maintenance of proper temperature and proper IV access to maintain hemodynamic stability and circulation of the patient by intravenous fluids. Dextrose stick monitoring with one drop of blood is done, if it comes $<40 \mathrm{mg} / \mathrm{dl}, 2 \mathrm{cc} / \mathrm{kg}$ of $10 \%$ dextrose is intravenously given, followed by a maintenance glucose infusion rate at $6 \mathrm{mg} / \mathrm{kg} / \mathrm{min}$. Simultaneously blood is collected for ionised calcium, if it comes less than $1 \mathrm{mmol} / \mathrm{L}, 2 \mathrm{ml} / \mathrm{kg}$ of $10 \%$ calcium gluconate is slowly given intravenously under heart rate monitor- 
ing. If seizures persist despite above measures than Inj. phenobarbitone is given in a loading dose of $20 \mathrm{mg} / \mathrm{kg}$ over 15 minutes. If seizures recur than a repeat loading dose of $10 \mathrm{mg} / \mathrm{kg}$ is given to a maximum of $30 \mathrm{mg} / \mathrm{kg}$. If seizures persist, loading dose of phenytoin is given at $20 \mathrm{mg} / \mathrm{kg}$ at $1 \mathrm{mg} / \mathrm{kg} / \mathrm{min}$ rate. If seizures still persist, then a repeat loading dose of phenytoin is given at $10 \mathrm{mg} /$ $\mathrm{kg}$. If the neonate still has seizures despite these medications then alternative drugs like levetiracetam is used in loading dose of 20 $\mathrm{mg} / \mathrm{kg}$ followed by maintenance dose of the above drugs. Other drugs which we used are Inj. lorazepam in bolus doses to control seizures, Inj. midazolam in similar way.

\section{Data analysis}

The data obtained from all patients was tabulated in predesigned case report form. A probability value of $<0.05$ was taken as level of significance as per chi square test. After data collection, data entry was done in Excel. Data analysis is done with the help of SPSS Software ver. 15. Qualitative data is presented with the help of Frequency and Percentage table, association among study group is assessed with the help of Chi-Square test. P value less than 0.05 is taken a significant level.

\section{Observation and Results}

At level-II newborn intensive care unit was a Hospital based, observational, prospective study, conducted on the newborns admitted in level 2 NICU from October 2015 to September 2017 in the Department of Paediatrics, JLN Hospital and Research Centre (C.G.). Total 150 newborns with seizure were enrolled in this study. The data was collected, analysed and observations in form of tables are as follows.

\begin{tabular}{|l|c|c|}
\hline Sex & Frequency & Percentage \\
\hline Male & 85 & 56.67 \\
\hline Female & 65 & 43.33 \\
\hline Gestation & Frequency & Percentage \\
\hline Full term & 112 & 74.67 \\
\hline Preterm & 35 & 23.33 \\
\hline Post term & 3 & 2 \\
\hline Weight (Kg) & Frequency & Percentage \\
\hline Less than 1.5 & 4 & 2.67 \\
\hline 1.5 to 2.5 & 43 & 28.67 \\
\hline More than 2.5 & 103 & 68.67 \\
\hline
\end{tabular}

Table 1: Demographic profile of study group.
The above table shows the detailed demographic details of our study group in relation to sex, maturity and birth weight. Amongst our 150 subjects with seizures we had a total number of male neonates in our study were 85 (56.67\%), and female neonates are $65(43.33 \%)$. Also, the table reveals that the total number of full term neonates in our study is 112 (74.67\%), preterm 35 (23.33\%) and $3(2 \%)$ post term neonates. Most neonates 103 (68.67\%) in study are in more than $2.5 \mathrm{~kg}$ birth weight followed by neonates $43(28.67 \%)$ have birth weight $1.5 \mathrm{~kg}$ to $2.5 \mathrm{~kg}$ and $4(2.67 \%)$ neonates are in less than $1.5 \mathrm{~kg}$ birth weight.

\begin{tabular}{|l|c|c|}
\hline Etiology & N & Percentage \\
\hline Birth asphyxia & 64 & 42.67 \\
\hline Metabolic & 57 & 38 \\
\hline Meningitis & 13 & 8.67 \\
\hline NN hyperbilirubinemia & 3 & 2 \\
\hline Cerebro vascular & 4 & 2.67 \\
\hline $5^{\text {th }}$ day seizure & & 0.67 \\
\hline Hypoxia & 4 & 2.67 \\
\hline Unknown & 4 & 2.67 \\
\hline
\end{tabular}

Table 2A: Etiology of seizures in the study group.

The above table shows that the most common cause of neonatal seizures in our study was Birth asphyxia accounting for 64 (42.67\%) cases, followed by metabolic cause in 57 (38\%) cases (including hypocalcemia, hypoglycemia, hypernatremia). This was followed by Meningitis in 13 (8.67\%) cases, 4 (2.67\%) cases of cerebrovascular, hypoxia and unknown cause each.

\begin{tabular}{|l|c|c|}
\hline Etiology & N & Percentage \\
\hline Birth asphyxia & 64 & 42.67 \\
\hline Metabolic & 57 & 38 \\
\hline Hypocalcemia & 28 & 18.67 \\
Hypoglycemia & 22 & 14.67 \\
Hypernatremia & 7 & 4.67 \\
\hline Meningitis & 13 & 8.67 \\
\hline NN hyperbilirubinemia & 3 & 2 \\
\hline Cerebro vascular & 4 & 2.67 \\
\hline Subdural haemorrhage & 2 & 1.33 \\
Intracerebral haemorrhage & 2 & 1.33 \\
\hline 5t day seizure & 1 & 0.67 \\
\hline Hypoxia (complex CHD) & 4 & 2.67 \\
\hline Unknown & 4 & 2.67 \\
\hline
\end{tabular}

Table 2B: Stratified etiology of seizures in study group. 
On further stratification of etiologies in our study, we found that hypocalcemia was the most common metabolic cause of seizures in $28(18.67 \%)$ cases. There were $22(14.67 \%)$ cases of hypoglycemia while 7 (4.67\%) cases of hypernatremia. 4 cases of Cerebrovascular causes were there, out of which 2 cases are due to Subdural haemorrhage and 2 cases due to Intracerebral haemorrhage 4 cases of hypoxic convulsion were case of complex cyanotic heart disease whereas 4 cases remain undiagnosed hence considered under unknown etiology.

\begin{tabular}{|c|c|c|c|}
\hline & Seizure Type & Frequency & Percentage \\
\hline 1 & Clonic & 30 & 20 \\
\hline 2 & Tonic & 38 & 25.33 \\
\hline 3 & Myoclonic & 1 & 0.67 \\
\hline 4 & Subtle & 81 & 54 \\
\hline
\end{tabular}

Table 3: Spectrum of seizure types in our study.

In our study Subtle type of seizures was the most common type accounting for 81 (54\%) cases, followed by Tonic type accounting for $38(25.33 \%)$ cases and clonic type of seizures in 30 (20\%) cas- es. Myoclonic type accounted for only 1 case $(0.67 \%)$ in our study.

\begin{tabular}{|l|c|c|}
\hline DOL & Frequency & Percentage \\
\hline Day 1 & 51 & 34 \\
\hline Day 2 to 3 & 55 & 36.67 \\
\hline 4 to 7 days & 39 & 26 \\
\hline More than 7 days & 5 & 3.33 \\
\hline
\end{tabular}

Table 4: Distribution of subjects as per of onset of seizure (DOL).

The above table reveals that maximum subjects 55 (36.67\%) cases had seizure onset on day of life 2 to 3, followed by 51 (34\%) cases had seizures onset on first day of life. 39 (26\%) cases had seizure onset on day of life 4 to 7 and 5 (3.33\%) cases had onset of seizures after $7^{\text {th }}$ day of life.

In our series we had 112 full term neonates (74.67\%), 35 preterm $(23.33 \%)$ neonates and 3 post-term (2\%) neonates. The above table shows that on comparison between gestation and etiology, Birth asphyxia are the most common cause of seizures in both preterm 17 (48.57\%) and full term 46 (41.07\%) neonates.

\begin{tabular}{|c|c|c|c|c|}
\hline & Preterm & Term & Post term & \\
\hline \multirow{2}{*}{ Birth Asphyxia } & 17 & 46 & 1 & 64 \\
\hline & $48.57 \%$ & $41.07 \%$ & $33.33 \%$ & $42.67 \%$ \\
\hline \multirow{2}{*}{ Metabolic } & 13 & 43 & 1 & 57 \\
\hline & $37.14 \%$ & $38.39 \%$ & $33.33 \%$ & $38 \%$ \\
\hline \multirow{2}{*}{ Meningitis } & 3 & 10 & 0 & 13 \\
\hline & $8.57 \%$ & $8.93 \%$ & $00 \%$ & $8.67 \%$ \\
\hline \multirow{2}{*}{$\begin{array}{l}\text { NN } \\
\text { Hyperbilirubinemia }\end{array}$} & 0 & 3 & 0 & 3 \\
\hline & $00 \%$ & $2.68 \%$ & $00 \%$ & $2 \%$ \\
\hline \multirow{2}{*}{ Cerebrovascular } & 0 & 4 & 0 & 4 \\
\hline & $00 \%$ & $3.57 \%$ & $00 \%$ & $2.67 \%$ \\
\hline \multirow{2}{*}{$5^{\text {th }}$ Day seizure } & 0 & 1 & 0 & 1 \\
\hline & $00 \%$ & $0.89 \%$ & $00 \%$ & $0.67 \%$ \\
\hline \multirow{2}{*}{ Нypoxia } & 1 & 3 & 0 & 4 \\
\hline & $2.86 \%$ & $2.68 \%$ & $00 \%$ & $2.67 \%$ \\
\hline \multirow{2}{*}{ Unknown } & 1 & 2 & 1 & 4 \\
\hline & 2.86 & $1.79 \%$ & $33.33 \%$ & $2.67 \%$ \\
\hline \multirow{2}{*}{ Total } & 35 & 112 & 3 & 150 \\
\hline & $100 \%$ & $100 \%$ & $100 \%$ & $100 \%$ \\
\hline
\end{tabular}

Table 5: Relationship between etiology and gestation. 
Metabolic abnormalities was the $2^{\text {nd }}$ most common cause of seizures in full terms 43 (38.39\%), however metabolic abnormalities accounted for 13 (37.14\%) case in the preterm group. Overall, Metabolic abnormalities is the $2^{\text {nd }}$ most common cause of seizure in this study. The statistical analysis is not significant such that exact association between a particular etiology and gestation age cannot be predicted. All cases of neonatal seizures secondary to hy- perbilirubinemia were in full term babies accounting for 3 (2.68\%) cases of full term. Meningitis accounted for 13 (8.67\%) cases, out of which $3(8.57 \%)$ cases in preterm babies and $10(8.93 \%)$ cases in term babies in our series. All 4 cases of cerebrovascular causes were encountered in the full term babies. Out of 4 neonates $(2.67 \%)$ in who cause of seizure could not be ascertained, 2 were full term and 1 each of preterm and post term age group.

\begin{tabular}{|c|c|c|c|c|c|}
\hline \multirow{2}{*}{ Etiology } & \multicolumn{4}{|c|}{ DOL } & \multirow{2}{*}{ Total } \\
\hline & Day 1 & Day 2 to 3 & Day 4 to 7 & Day $>7$ & \\
\hline \multirow{2}{*}{ Birth Asphyxia } & 44 & 19 & 1 & 0 & 64 \\
\hline & $68.75 \%$ & $29.69 \%$ & $1.56 \%$ & $00 \%$ & $100 \%$ \\
\hline \multirow{2}{*}{ Metabolic } & 5 & 23 & 27 & 2 & 57 \\
\hline & $8.77 \%$ & $40.35 \%$ & $47.37 \%$ & $3.51 \%$ & $100 \%$ \\
\hline \multirow{2}{*}{ Meningitis } & 0 & 5 & 5 & 3 & 13 \\
\hline & $00 \%$ & $38.46 \%$ & $38.46 \%$ & $23.08 \%$ & $100 \%$ \\
\hline \multirow{2}{*}{ Neonatal Hyperbilirubinemia } & 0 & 2 & 1 & 0 & 3 \\
\hline & $00 \%$ & $66.66 \%$ & $33.33 \%$ & $00 \%$ & $100 \%$ \\
\hline \multirow{2}{*}{ Cerebrovascular } & 2 & 0 & 2 & 0 & 4 \\
\hline & $50 \%$ & $00 \%$ & $50 \%$ & $00 \%$ & $100 \%$ \\
\hline \multirow{2}{*}{$5^{\text {th }}$ day Seizure } & 0 & 0 & 1 & 0 & 1 \\
\hline & $00 \%$ & $00 \%$ & $100 \%$ & $00 \%$ & $100 \%$ \\
\hline \multirow{2}{*}{ Hypoxia } & 0 & 3 & 1 & 0 & 4 \\
\hline & $00 \%$ & $75 \%$ & $25 \%$ & $00 \%$ & $100 \%$ \\
\hline \multirow{2}{*}{ Unknown } & 0 & 3 & 1 & 0 & 4 \\
\hline & $00 \%$ & $75 \%$ & $25 \%$ & $00 \%$ & $100 \%$ \\
\hline \multirow{2}{*}{ Total } & 51 & 55 & 39 & 5 & 150 \\
\hline & $34 \%$ & $36.67 \%$ & $26 \%$ & $3.33 \%$ & $100 \%$ \\
\hline
\end{tabular}

Table 6: Association between etiology and day of life (DOL).

Our study reveals that neonatal seizure due to birth asphyxia is most common on $1^{\text {st }}$ day of life accounting for $44(68.75 \%)$ cases, which accounts for $44 / 51(86.27 \%)$ cases of neonatal seizure on $1^{\text {st }}$ day of life. The statistical analysis is significant suggesting that birth asphyxia is the most common cause of seizure on day 1 of life. Metabolic causes are most common cause in day of life $2^{\text {nd }}$ to $3^{\text {rd }}$, $23 / 55(41.82 \%)$ cases and day of life $4^{\text {th }}$ to $7^{\text {th }}, 27 / 39(69.23 \%)$ cases. Meningitis is most common cause of seizure after day $7^{\text {th }}$ of life, $3 / 5(60 \%)$ cases. Seizures secondary to neonatal hyperbilirubinemia encephalopathy did not follow any specific time period, similar is the true for seizures secondary to meningitis, cerebrovascular accident and hypoxic seizure. $5^{\text {th }}$ day seizures as per definition occurred on day of life 4 to 6 .
In our series the data revealed that out of total 150 cases of seizures, 112 (74.67\%) cases occurred in full term, 35 (23.33\%) cases in preterm and $3(2 \%)$ cases in post term. Amongst these cases 81 (54\%) were of Subtle type, in which $65(80.24 \%)$ cases were in full term, $15(18.52 \%)$ cases were in preterm while $1(1.23 \%)$ cases were in post term. This was followed by tonic seizure type occurring in 38 cases (25.33\%), in which 29 (76.32\%) in full term and $9(23.68 \%)$ in preterm. The statistical analysis was not significant in our study and therefore we could not ascertain a particular type of seizure that is more common at a particular gestational age. Clonic seizure type followed the above seizure types occurring in $30(20 \%)$ cases out of which 17 (56.67\%) full term neonates, 11 $(36.67 \%)$ preterm and $2(6.67 \%)$ post term neonates. 
There was only 1 case of myoclonic seizure which occurred in full term neonate.

In our series as shown in above table Birth Asphyxia which accounted for most common type of seizure in 64 neonates, had subtle type of seizure in 37 (57.81\%) neonates followed by tonic type in 20 (31.25\%) cases and clonic type in remaining 7 (10.94\%) cases. The $2^{\text {nd }}$ most common cause of seizure in our series was metabolic abnormalities in 57 neonates in which subtle type was most common seizure type in 33 (57.89\%) cases followed by 16 (28.07\%) neonates having clonic type of seizure, 8 (14.04\%) neonates had tonic type. The statistical analysis is not significant such that exact association between a particular type of seizure and its etiology cannot be predicted. Among the 13 cases of seizures due to meningitis 7 (53.85\%) cases had subtle seizure and $3(23.08 \%)$ each of tonic and clonic type. Out of the 3 cases of seizures due to hyperbilirubinemia $2(66.67 \%)$ cases were of tonic type and 1 case $(14.3 \%)$ had subtle seizure. Among seizures due to Cerebrovascular causes 2 (50\%) were of subtle type and 1 (25\%) cases each of tonic and clonic type. Hypoxic seizure 2 (50\%) were of tonic type and 1 (25\%) cases each of subtle and clonic type. Among seizures due to unknown causes 2 (50\%) were of clonic type and 1 $(25 \%)$ cases each of tonic and myoclonic type. 5th day seizure has $1(100 \%)$ tonic type of seizure.

Our study reveals that $112(74.67 \%)$ full term neonates had seizures while $35(23.33 \%)$ preterm neonates and $3(2 \%)$ post term neonate had seizures. The statistical association is significant such that seizures occurred most commonly in full term neonates. Out of all (112) full term neonates, 23 (20.53\%) neonates are IUGR babies (Birth weight less than $2.5 \mathrm{~kg}$ ), while 89 (79.46\%) neonates are appropriate for gestational age. Out of 35 preterm neonates 3 $(8.57 \%)$ have birth weight less than $1.5 \mathrm{~kg}$.

We also saw association of hypoglycemic seizures as per day of life. The table shows that the hypoglycemic seizures most commonly occurred on day 4 to 7 of life accounting for $13(59.09 \%)$ cases. 7 cases (31.82\%) occurred on day 2 to 3 of life. While $1(4.55 \%)$ case occurred on day 1 of life and after day 7 of life each. The statistical association is significant such that hypoglycemic seizures occurred most commonly on day 4 to 7 of life.

As per our study hypocalcemic seizures most commonly occurred on day 2 to 3 of life accounting for 15 (53.57\%) cases. While $9(32.14 \%)$ cases occurred on day 4 to 7 of life and $4(14.29 \%)$ cases on day 1 of life. The statistical association is significant such that hypocalcemic seizures occurred most commonly on day 2 to 3 of life.

\section{Discussion}

Neonatal seizures are overt manifestations of neurological dysfunction in the newborn and usually manifest as stereotypic muscular activity or autonomic changes [4]. Seizures in the neonatal period are the most common neurological emergency encountered and are associated with high morbidity and mortality. The incidence of neonatal seizures is 2.8 per 1000 in infants with birth weights of more than $2500 \mathrm{~g}$ to 57.5 per 1000 in very low birth weight infants [1]. We conducted a single centre, prospective, noninterventional observational study of consecutive neonates admitted in neonatal intensive care unit. We evaluated 150 neonates with seizures admitted to NICU in our centre from October 2015 to September 2017. All subjects were evaluated on a clinical basis; physical examination was done to look for vitals, blood pressure, and cyanosis.

\section{Demographic profile}

During our study period of two years (October 2015 to September 2017), total of 2503 neonates were admitted in our neonatal intensive care unit of which 150 neonates had seizures. The incidence of neonatal seizures in hospitalised neonates at our centre was $2.83 \%$. As compared to this, the incidence of seizures in study carried out by Sheth R, Hobbs G, Mullett M [18] was 8.6\%. The incidence of seizure in various studies carried out varied from $2.4 \%$ to $19.2 \%$ in following workers as $2.4 \%$ in study by Moayedi AR, Zakeri S,Moayedi F [19], 2.6\% in Eghbalian F, Monsef A, Taghdiri MM [20] study and 19.2\% in Digra SK, Gupta A [21] study.

In our study the males outnumbered females, accounting for 85 (56.67\%) cases, while females were 65 (43.33\%) cases which is in accordance with the studies carried out by Moayedi AR, Zakeri S, Moayedi F [13], in which 64 were male (58.2\%) and 46 female $(41.8 \%)$ and in study carried out by Eghbalian F, Monsef A, Taghdiri MM [19] 25/34 (73.55\%) were males, 9/34 (26.5\%) were females. A similar type of finding was seen in study done by Digra SK, Gupta A [22], in which 72 out of 102 neonates were males and remaining 30 were females. The male to female ratio in our study was 1.3:1. This preponderance of males over females in our study could be due to social beliefs that male babies are cared better by their parents and are brought to the hospital even with minor complaints but female babies are usually neglected and are managed at home even if they are very sick. 
In our case series full term neonates accounted for 112 (74.67\%) cases while preterm accounted for 35 (23.33\%) cases and post term accounted for $3(2 \%)$, which is consistent with other studies like Marzoki JMA [23], in which 84 out of 88 (95.4\%) full term neonates had seizures. Majority of neonates 103 (68.67\%) in our study have their birth weights more than $2.5 \mathrm{~kg}$, while 43 (28.67\%) neonates have birth weights in the range of 1.5 to $2.5 \mathrm{~kg}$ and $4(2.67 \%)$ neonates have birth weight less than $1.5 \mathrm{~kg}$. This was consistent with other studies like Eghbalian F, Monsef A, Taghdiri MM [19], Digra SK, Gupta A [20], Marzoki JMA [24], in which the majority of neonates had the birth weights more than $2.5 \mathrm{~kg}$. Though our study has majority of full term and post term (115) neonates, few cases had intra uterine growth retardation which is the reason why even being full term few cases had birth weight in 1.5 to $2.5 \mathrm{~kg}$ group.

\section{Association of seizure with onset as per day of life}

In our series, 55 out of 150 neonates (36.67\%) have their seizure onset on day of life 2 and 3, 51 (34\%) neonates had seizure onset in first 24 hours of life while 39 (26\%) neonates had seizure onset on day 4 to 7 of life and 5 (3.33\%) neonates had seizures after 7 days of life. In our study there was almost equal incidence of seizures on day of life 2 to 3 and first 24 hours of life. As against this the other study done by Digra SK, Gupta A [20], seizure onset was most common in first 24 hours of life accounting for $45.09 \%$, while on day of life 2 and 3 seizures accounted for $25.49 \%$. Whereas in a study carried out by Marzoki JMA [24], most seizures occurred on day of life 3 to 7 accounting for $43.2 \%$, followed by seizure in first two days of life $29.5 \%$. As against this in a study carried out by Moayedi AR, Zakeri S, Moayedi F [13], 32 (29.1\%) neonates had seizures in the first $24 \mathrm{hr}$ of their life, 28 (25.5\%) on the second and third days of life, $14(12.7 \%)$ between the $4^{\text {th }}$ to $6^{\text {th }}$ days of life and $36(32.7 \%)$ on the $7^{\text {th }}$ day or later. The results of this study were almost similar to our study.

\section{Type of seizure}

In our series the most common seizure type was subtle seizure in 81 out of 150 neonates (54\%), followed by tonic in 38 (25.33\%) cases and clonic type in 30 (20\%) cases. In other study carried out by Moayedi AR, Zakeri S, Moayedi F [13] the most common type of seizures observed was subtle (39.1\%); the other types seen were myoclonic (17.3\%), generalized tonic clonic seizures (GTCS) $(12.7 \%)$, clonic $10 \%$, tonic $7.3 \%$, and in fifteen cases $(13.6 \%)$ type of seizure was not mentioned. In another study carried out by Digra SK, Gupta A [21], majority 37.25\% (38) neonates had multifocal clonic seizures followed by $26.47 \%, 23.52 \%, 12.74 \%$ subtle, tonic and focal clonic seizures respectively. As against all this, most common seizure type was subtle in 28/88 (33.3\%) neonates followed by tonic type of seizure in 18 (21.4\%) neonates in a study done by Marzoki JMA.

\section{Etiology of seizure}

In our study the most common cause of seizure was birth asphyxia (HIE) accounting for 64/150 (42.67\%) cases. Metabolic abnormalities is $2^{\text {nd }}$ most common cause accounting for $57 / 150$ (38\%) out of which hypocalcemia accounted for the most common cause in 28 (49.12\%) out of 57 cases of metabolic causes followed by hypoglycemia in $22(38.6 \%)$ cases out of total 57 metabolic cases and there was 7 (12.28\%) case of hypernatremia. It was followed by meningitis in $13(8.67 \%)$ cases. There were $4(2.67 \%)$ cases each of cerebrovascular cause, hypoxia and unknown cause. As compared to our study, the most common etiology of neonatal seizures in study carried out by Moayedi AR, Zakeri S, Moayedi F [25] was HIE (36.4\%) similar to our study, followed by infections (19.1\%), metabolic disorders and inborn errors of metabolism (7.3\%), Intra Cranial Haemorrhage (ICH) (2.7\%) and structural disorders (1.8\%); in thirty six cases (32.7\%) the etiology was not defined. In other study done by Eghbalian F, Monsef A, Taghdiri MM [19], the most common etiology of seizure was metabolic unlike our study, but here hypocalcemia was most common metabolic abnormality as in our study. In this study hypoglycemia accounted for $9(26.5 \%)$ cases. Birth asphyxia accounted for $2^{\text {nd }}$ most common cause of seizure. In another study done by Digra SK, Gupta A [22], birth asphyxia is the most common cause accounting for $67.65 \%$ cases similar to our study followed by infections (septicaemia and meningitis). In another study carried out by Marzoki JMA [24], metabolic disturbances is most common cause collectively accounted for $47.7 \%$ cases, followed by birth asphyxia in $15.4 \%$ cases. But in this study hypomagnesaemia was most common metabolic abnormality observed as against hypocalcemia in our study.

\section{Relation of etiology with seizure type}

In our series we found that birth asphyxia (HIE) were the most common etiology of seizure amongst which 37 (57.81\%) cases were of subtle type, 20 (31.25\%) cases were of tonic type, followed by $7(10.94 \%)$ cases of clonic type. But there was no significant statistical association between seizure type and etiology.

Seizures due to metabolic abnormalities had 33 (57.89\%) cases were of subtle type, 16 (28.07\%) of clonic type and 8 (14.04\%) of subtle type. 


\section{Hypoglycemic convulsions}

In our study hypoglycemia is the $2^{\text {nd }}$ most common metabolic abnormality responsible for convulsion, 13 (59.09\%) cases occurred on day of life 4 to 7 , followed by 7 (31.82\%) cases between 2 to 3 day of life and 1 (4.55\%) case each on day 1 of life and after day 7 of life. The statistical association is significant such that hypoglycaemic seizures occurred most commonly on day 4 to 7 of life. As compared to this in a study done by Marzoki JMA [24], majority of hypoglycaemic convulsions (60\%) occurred in first 2 days of life followed by $20 \%$ cases occurring in 3 to 7 days of life and after day 7 of life.

\section{Hypocalcemic convulsions}

In our study hypocalcemia is the most common metabolic abnormality responsible for convulsion, 15 (53.57\%) cases occurred on day 2 to 3 of life followed by 9 (32.14\%) cases on day 4 to 7 of life and 4 (14.29\%) cases on day 1 of life. The statistical association is significant such that hypocalcemic seizures occurred most commonly on day 2 to 3 of life. As compared to this in a study done by Marzoki JMA [24], 54.5\% cases occurred in first two days of life followed by $36.4 \%$ cases occurring in day of life 3 .

\section{Pharmacotherapy}

In our series the most common antiepileptic drug used was phenobarbitone 133 (88.67\%) which is in accordance to the literature and studies done in which most neonatologists prefer phenobarbitone over other drugs due to its neuroprotective effect and in spite of some studies showing its long term harmful effect on neurodevelopmental aspect [26]. 14 (9.33\%) cases required combined use of phenobarbitone and phenytoin to control seizures, while 3 (2\%) cases required combined use of phenobarbitone, phenytoin and levetiracetam. The use of levetiracetam was in accordance to the newer literature in which drugs like levetiracetam and topiramate can be used safely in neonatal seizures after phenobarbitone and phenytoin $[26,27]$.

\section{Outcome}

In our series of total 150 neonates enrolled at our centre, 8 neonates expired secondary to septicaemia and complex congenital heart disease. 142 cases were discharged out of which many case of birth asphyxia are still under regular follow up. Few cases had resistant seizures for which they are on levetiracetam.

\section{Conclusion}

Incidence of neonatal seizures in hospitalised NICU graduates was $2.83 \%$. Seizures were seen in both full term and Preterm Neo- nates. The male to female ratio in our study was 1.3:1. The most common cause of neonatal seizures in our study was birth asphyxia followed by metabolic abnormalities. This cause of seizure was the most common cause of seizure on day 1 of life. In our study subtle type of seizure was the most common type. Following this we had tonic type of seizure, which were followed by clonic type.

Maximum cases of seizure had their seizure onset in day of life 2 to 3, followed by onset on day of life 1 neonates had seizures. The most common antiepileptic drug used was phenobarbitone (PHB) in a few cases both phenobarbitone and phynetoin is required and minimal cases required combined use of phenobarbitone, phenytoin and levetiracetam.

\section{Bibliography}

1. Sankar JM., et al. "Seizures in newborn". Indian Journal of Pediatrics 75 (2008): 149.

2. Volpe JJ. "Hypoxic-Ischemic Encephalopathy: Biochemical and Physiological Aspects". In: Neurology of the Newborn. $4^{\text {th }}$ edition. Philadelphia: WB Saunders (2000): 217-76.

3. Tekgul H., et al. "The current etiologic profile and neurodevelopmental outcome of seizures in term newborn infants". Pediatrics 117 (2006): 1270-1280.

4. McCabe BK., et al. "Reduced Neurogenesis after Neonatal Seizures”. Journal of Neuroscience 21.6 (2001): 2094-2103.

5. Sheth RD and Bodensteiner JB. "Delayed postanoxic encephalopathy: possible role for apoptosis". Journal of Child Neurology 13.7 (1998): 347-348.

6. Kossoff E. "Neonatal Seizures Due to Hypoxic-Ischemic Encephalopathy: Should We Care?" Epilepsy Currents 11 (2011): 147-148.

7. Rennie JM. "Neonatal seizures". European Journal of Neuroscience 156 (1997): 83-87.

8. Tekgul H., et al. "The current etiologic profile and neurodevelopmental outcome of seizures in term newborn infants". Pediatrics 117 (2006): 1270-1280.

9. Jensen FE. "Neonatal Seizures: An Update on Mechanisms and Management". Clinical Perinatology 36.4 (2009): 881.

10. Scher MS., et al. "Neonates with electrically confirmed seizures and possible placental associations". Pediatric Neurology 19.1 (1998): 37-41.

11. Fakhraee SH. "Neonatal Seizures: A Review". Iranian Journal of Child Neurology (2007): 7-11. 
12. Rennie JM and Bylan GB. "Neonatal seizures". In David TJ, ed. Recent advances in paediatrics 18. Churchill Livingstone, Edinburgh (2002): 19-32.

13. Larioa N. "Current Controversies in Diagnosis and Management of Neonatal Seizures". Indian Pediatrics 37 (2000): 367372.

14. Bernes SM and Kaplan AM. "Evolution of neonatal seizures". Pediatric Clinics of North America 41.5 (1994): 1069-1104.

15. http://formulas.tutorvista.com/math/statistics-formulas. html

16. Roberton NRC and Smith MA. "Early neonatal hypocalcemia". Archives of Disease in Childhood 50 (1975): 604-609.

17. McGowan JE. "Neonatal Hypoglycemia”. Pediatrics Review 20 (1999): e6-e15.

18. Sankar R and Painter MJ. "Neonatal seizures: after all these years we still love what doesn't work". Neurology 64.5 (2005): 776-777.

19. Eghbalian F., et al. "Neonatal Seizures: Etiology and Frequency". Iranian Journal of Child Neurology (2007): 39-42.

20. Sheth R., et al. "Neonatal Seizures: Incidence, Onset, and Etiology by Gestational Age". Journal of Perinatology 19.1 (1999): 40-43.

21. Silverstein FS and Jensen FE. "Neonatal Seizures". Annuals of Neurology 62 (2007): 112-20.

22. Digra SK and Gupta A. "Prevalence of Seizures in Hospitalized Neonates". JK Science Journal of Medical Education and Research 9 (2007): 27-29.

23. Villeneuve N., et al. "Neonatal seizures induced persistent changes in intrinsic properties of CA1 rat hippocampal cells". Annuals of Neurology 47 (2000): 729-38.

24. Marzoki JMA. "Clinico-Biochemical profile of neonatal seizures [Research Thesis]". Hilla-Iraq- Babylon: Babylon University (2009).

25. Moayedi AR., et al. "Neonatal Seizure: Etiolgy and Type". Iranian Journal of Child Neurology (2007): 23-26.

26. Sheth RD., et al. "Midazolam in the treatment of refractory neonatal seizures”. Clinical Neuropharmacology 19.2 (1996): 165-170.

27. Chapman KE., et al. "Neonatal seizures: controversies and challenges in translating new therapies from the lab to the isolette". European Journal of Neuroscience 35 (2012): 18571865.

\section{Assets from publication with us}

- Prompt Acknowledgement after receiving the article

- Thorough Double blinded peer review

- Rapid Publication

- Issue of Publication Certificate

- High visibility of your Published work

Website: www.actascientific.com/

Submit Article: www.actascientific.com/submission.php

Email us: editor@actascientific.com

Contact us: +919182824667 